\title{
Development of fat digestion in infancy
}

\author{
W G Manson, W A Coward, M Harding, L T Weaver
}

\begin{abstract}
Aim-To measure the development of fat digestion in early life, using a stable isotope breath test.

Methods-A combined longitudinal and cross sectional study was performed on 30 term and preterm infants using ${ }^{13} \mathrm{C}$ labelled mixed triglyceride (MTG). Seventy six tests were performed in all. Results were expressed as cumulative percentage dose recovered over 6 hours (cPDR).

Results-Eighteen of 34 tests performed on infants under 30 days of age showed cPDRs below the normal range for adults and older children. The remainder of tests, performed on infants over 57 days of age, all showed cPDRs within the normal range. Peak PDR correlated significantly $(\mathbf{r}=0.928, \mathrm{p}<0.01)$ with $\mathbf{c P D R}$.

Conclusion-The capacity to digest fat is incomplete at birth, but quickly develops to normal levels during the first months of life. The MTG breath test is a useful noninvasive method to measure the development of fat digestion in early life.
\end{abstract}

(Arch Dis Child Fetal Neonatal Ed 1999;80:F183-F187)

Keywords: lipid; digestion; breath test; stable isotope

Forty five to fifty per cent of the energy requirement of neonates is provided by milk fat. Lipids help to transfer some vitamins, and recent work has shown that long chain polyunsaturated fatty acids (LCPUFA) have an important role in the development of neural ${ }^{1}$ and retinal tissues. ${ }^{2}$

Although a great deal is known about the mechanism of fat digestion in adults and children, ${ }^{3}$ little is known about the development of the digestive capacity of neonates. As long ago as 1961 it was suggested that the fat digestion of the infant was "immature": fat balance studies of formula fed infants showed absorption coefficients of $<95 \%$ up to the age of 18 months. ${ }^{4}$ Zoppi et $a \bar{l}$ used duodenal intubation and pancreozymin/secretin stimulation to measure exocrine pancreatic secretion in preterm and term neonates, and showed that enzyme values in duodenal juice were significantly lower than those of older children. In both studies fat digestion was measured indirectly rather than by measuring intraliminal lipolysis directly.

Stable isotopes offer a means of measuring fat digestion more directly in vivo. ${ }^{6}$ The "mixed triglyceride (MTG) breath test" measures intraduodenal lipolysis and has been used in adults ${ }^{7}$ and children. ${ }^{8}$ Ingested triglyceride, labelled with the stable isotope ${ }^{13} \mathrm{C}$, is digested, absorbed, and oxidised, releasing ${ }^{13} \mathrm{C}$-labelled carbon dioxide which can be detected in exhaled breath. Because the rate limiting step in the process is the hydrolysis of the triglyceride molecule, the recovery of ${ }^{13} \mathrm{CO}_{2}$ in the breath is an indirect measure of its lipolysis in the gastrointestinal tract. This study aimed to use the MTG breath test to measure the development of fat digestion in newborn infants.

\section{Methods}

Thirty infants, 26 term (11 boys, 15 girls), and four preterm (three boys, one girl, all of 32 weeks gestation) were studied between the ages of 1 and 234 days. They were recruited from the antenatal clinics, wards, and special care baby unit of the Maternity and Children's Hospitals.

Five tests were performed on children with specific diseases (investigation) to measure the effects of metabolic or pancreatic disease on the results. Three tests were performed on one adult to monitor the effect of serial warming of the MTG-olive oil mixture. The background variability of ${ }^{13} \mathrm{C}$ in breath was measured in four normal neonates (controls) by giving an identical test feed without the ${ }^{13} \mathrm{C}$ labelled MTG.

The study was both cross sectional and longitudinal in design. Depending on the day of delivery, the neonates were investigated once or twice during the first week, and thereafter six were followed longitudinally. The four preterm babies consisted of two sets of twins both born at 32 weeks. One set was investigated once at 10 days. The other set was fed nasogastrically and studied at 20 days and one twin again at 57 days. The five infants with metabolic or pancreatic abnormalities consisted of three children with failure to thrive, one child with neonatal diabetes and suspected pancreatic agenesis, and one child with a hepatic metabolic disorder.

The test molecule, the MTG 1,3-distearyl$2-{ }^{13} \mathrm{C}$-carboxy-octanoyl glycerol $(99 \%$ atom excess), was used as substrate to measure fat digestion. After ingestion this molecule undergoes lipolysis by preduodenal and pancreatic lipases which hydrolyse the stearic ester bonds at the $S n-1$ and $S n-3$ position, releasing the monoglyceride $2-{ }^{13} \mathrm{C}$-octanoyl glycerol or ${ }^{13} \mathrm{C}$ octanoate, a medium chain fatty acid. This is then absorbed across the mucosa and transported to the liver where it enters metabolic pathways, leading to the enrichment of bicarbonate, protein, fat and carbohydrate with ${ }^{13} \mathrm{C}$. The end product of oxidation is expired as ${ }^{13} \mathrm{CO}_{2}$. Measurement of the enrichment of ${ }^{13} \mathrm{CO}_{2}$ collected in the breath was used to assess the degree of intraliminal lipolysis. ${ }^{8}$

The weight and length of each subject were obtained at birth and on all test days. MTG $(800 \mathrm{mg}$ ) dissolved in $10 \mathrm{ml}$ of olive oil was 
warmed to $37^{\circ} \mathrm{C}$ and mixed before each test. The dose of MTG was 10 or $20 \mathrm{mg} / \mathrm{kg}$ for infants and $5 \mathrm{mg} / \mathrm{kg}$ for adults. Infants were given the MTG mixture during a normal feed, whether it was formula alone or with weaning foods. They were allowed to follow their normal feeding pattern throughout the test. The duration of fasting before the test, and the amount and type of feed taken in the previous 24 hours were recorded at the start of the test and during the test. The MTG-olive oil mixture was given directly from a syringe into the infant's mouth during the test meal or milk feed. Care was taken to note any regurgitation of the mixture or subsequent vomiting of the feed.

Adults were asked to abstain from foods naturally enriched with ${ }^{13} \mathrm{C}$ (for example corn and cane sugar) on the day before each test, and fasted from midnight. The test meal for adults consisted of two pieces of buttered toast and a glass of milk. They were allowed a light lunch of foods with low natural enrichment of ${ }^{13} \mathrm{C}$ after three hours of the test.

Duplicate breath samples were collected at $\mathrm{T}_{0}$ (before the test meal) and every 30 minutes for up to six hours thereafter. Breath was collected from infants using an anaesthetic mask, connected via a one way flap valve (Ambu International, Copenhagen, Denmark) to a sealed reservoir bag (Laerdal Medical Ltd, Orpington, UK). Adults exhaled into the valve without using the mask. ${ }^{9}$ The exhaled air was aspirated into a $10 \mathrm{ml}$ syringe and transferred to an evacuated glass tube (Exetainer, Labco, High Wycombe, UK).

${ }^{13} \mathrm{C}$ enrichment was measured using isotope ratio mass spectrometry (SIRA 10 Micromass, Wythenshawe, UK). The ${ }^{13} \mathrm{C}$ enrichment of each sample was expressed as the relative difference $(\delta)$ between the sample and an international limestone standard Peedee Belemnite (PDB) where:

$\delta^{13} \mathrm{C} \%=\left[\left(\mathrm{R}_{\mathrm{S}} / \mathrm{R}_{\mathrm{PDB}}\right)-1\right]:[(\mathrm{RS} / \mathrm{RPDB})-1] ; \mathrm{x} 10^{3}$ $\mathrm{R}_{\mathrm{S}}={ }^{13} \mathrm{C} /{ }^{12} \mathrm{C}$ in the sample $\mathrm{R}_{\mathrm{PDB}}={ }^{13} \mathrm{C} /{ }^{12} \mathrm{C}$ in $\mathrm{PDB}=0.0112372$

The percentage of MTG recovered was expressed for each 30 minute interval as percentage dose recovered (PDR) for the interval $t_{0}$ to $t_{+1}$ (min) using a formula described before. ${ }^{8}$ Cumulative PDR (cPDR) was obtained by summation of the single PDR values for each time interval. The results were expressed as cPDR at six hours, peak PDR (the maximum PDR achieved in any 30 minute time interval during the test), time to peak PDR and cPDR at the peak. We defined the normal range of cPDR as $20-42 \% .^{10}$

In 22 tests on normal neonates carbon dioxide production rate was measured using a Deltatrac indirect calorimeter (Datex, Helsinki, Finland). ${ }^{11}$ The infants were placed supine on a thin foam mattress in a standard 50 litre plastic cot sealed with a perspex lid, using rubber insulation tubing held in place by metal clips. There was an air inlet above the feet of the infant, and an expired air port at the level of the infant's head. Room air was drawn through the cot at a rate of 10 litres per minute and inspired and expired respiratory gases were analysed for oxygen and carbon dioxide content. Measurements were made about three hours after ingestion of the substrate, when 10 sequential minute readings of carbon dioxide production were obtained. These were averaged to obtain a value for carbon dioxide production rate in $\mathrm{ml} / \mathrm{min}$, which was converted to $\mathrm{mmol} / \mathrm{min}$ using the formula:

$$
\mathrm{mmol}=\frac{\mathrm{ml}}{\mathrm{R} \times\left(273.15+{ }^{\circ} \mathrm{C}\right)}
$$

where gas constant $\mathrm{R}=0.082061 / \mathrm{atm} / \mathrm{deg} / \mathrm{mole}$

In all other tests an estimated carbon dioxide production rate of $5 \mathrm{mmol} / \mathrm{m}^{2} / \mathrm{min}$ was used ${ }^{12}$ with body surface area calculated using Haycock's formula. ${ }^{13}$

Permission for this study was granted by the Yorkhill Hospitals Ethics Committee, and the study was performed with the informed written consent of the parents. Results were analysed using Excel (Microsoft, USA) and Minitab (Minitab Inc, Pennsylvania, USA) statistical packages, comparing expressions of PDR with each other and with age using linear regression with and without logarithmic transformation.

\section{Results}

Fifty nine tests were performed on term infants and five on preterm infants from among the 30 infants. Each of the five investigation and four control infants underwent a single test and the one adult underwent three tests. Eleven tests from the term infants were excluded from the analysis because of spillage of MTG-olive oil mixture at the time of the test, or vomiting within the first four hours of the test, leaving a total of 65 tests for analysis (table 1).

Forty eight tests were analysed from 26 term infants and five from four preterm infants. Figure 1 shows cPDR plotted against age for the term infants. In the neonatal period the cPDR ranged from 0 to $34 \%$. In 18 of the 34 tests performed on infants under 30 days of age the cPDR was below the range for healthy adults and older children. By 50 days of age all results lay within the normal range for adults and older children. The solid lines connect the results of six infants who underwent more than one test and were followed from birth up to between 60 and 240 days of age.

Figure 2 shows peak PDR plotted against cPDR with linear regression. There was a correlation of peak PDR $(\%)=0.134 \times \operatorname{cPDR}(\%)$ $+0.435(\mathrm{r}=0.93 ; \mathrm{p}<0.01)$. The correlation between $\mathrm{cPDR}$ at peak and $\mathrm{cPDR}(\mathrm{r}=0.77$, $\mathrm{p}=0.001$ ) was also significant but that between time to peak and $\mathrm{cPDR}(\mathrm{r}=0.047, \mathrm{p}=0.75)$ was not.

Table 1 Number of subjects, age range, and number of tests in each group

\begin{tabular}{lcll}
\hline Group & $\begin{array}{l}\text { No of } \\
\text { subjects }\end{array}$ & $\begin{array}{l}\text { Age range } \\
\text { (days) }\end{array}$ & $\begin{array}{l}\text { No of tests } \\
\text { performed } \\
\text { (analysed) }\end{array}$ \\
\hline Term infants & 26 & $1-234$ & $59(48)$ \\
Preterm infants & 4 & $10-57$ & 5 \\
Investigation & 5 & $35-602$ & 5 \\
Adults & 1 & $1-4$ & 3 \\
Controls & 4 & $1-4$ & $76(65)$ \\
Total & 40 & & 76 \\
\hline
\end{tabular}




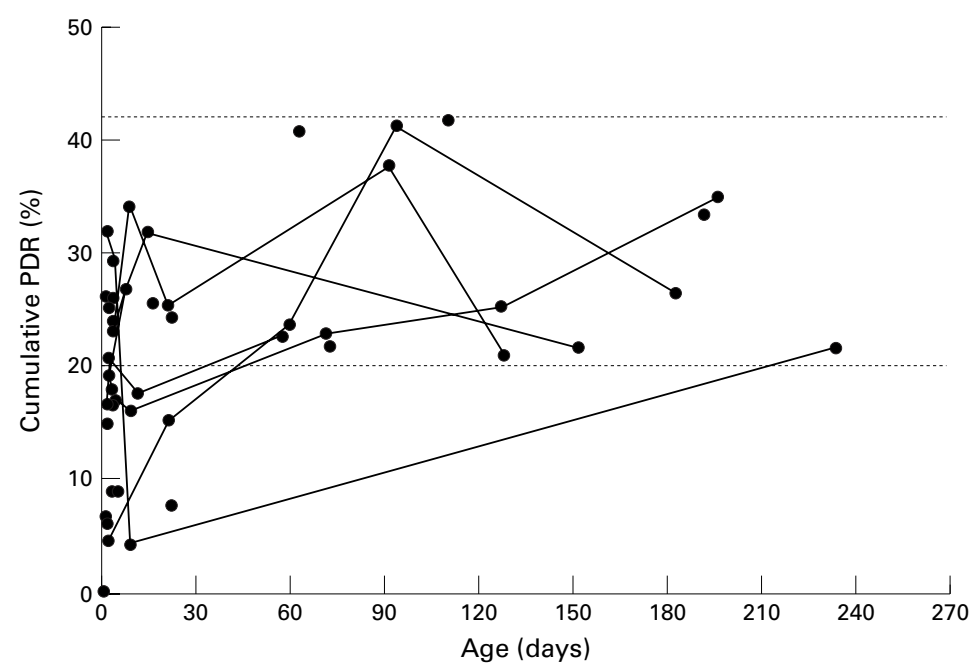

Figure 1 Cumulative PDR (\%) plotted against age (days) for term infants. Upper and lower limits of normal range are shown by dotted lines. Solid lines connect results for six infants who were tested on more than one occasion over four months.

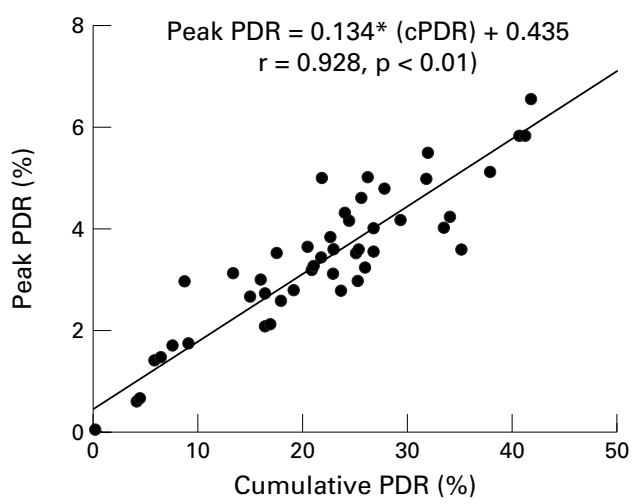

Figure 2 Peak PDR plotted against cPDR for term infants.

Three of the five tests conducted on preterm infants (at ages 10,20, and 20 days) showed no rise in $\delta$ above baseline during the course of the tests. One of these originally tested at 20 days was retested at 57 days when he had a $\mathrm{CPDR}$ of $27.8 \%$. One baby tested at 10 days showed a cPDR of $13.3 \%$.

The five patients who underwent tests for investigation of malabsorption or failure to thrive had cPDRs ranging from $9.6 \%$ to $34.1 \%$. Cases 1 and 3 were the only infants with suspected pancreatic or hepatic disease at the time of the test and showed cPDRs below the normal range at $9.6 \%$ and $16 \%$. The three highest baselines $(-17.5 \%,-19.0 \%$, and $-20.9 \%$ ) were in this group. All three were taking dietary supplements containing corn syrup which is rich in ${ }^{13} \mathrm{C}$. All others were within the range, suggesting avoidance of ${ }^{13} \mathrm{C}$-rich foods.

The one adult was tested three times with the same batch of MTG mixture after rewarming once, three, and six times. She had cPDRs of $26.8 \%, 18.3 \%$, and $27.1 \%$, respectively. The four controls were all full term, 1, 2, 3 and 4 days of age, and had a mean (SD) weight of $3.73(0.40) \mathrm{kg}$. The variability over 6 hours was less than $0.7 \delta \%$ in each case with a mean (SD) of $0.52(0.259) \delta \%$. Mean baseline $\delta$ for all

\section{Key points}

- Indirect evidence suggests that neonates have a limited capacity to digest dietary fat

- Using a ${ }^{13} \mathrm{C}$-labelled mixed triglyceride, infants show a rapid maturation in intraluminal fat digestion during the early months of life

- Stable isotope breath tests are a safe, simple, reproducible non-invasive way of measuring the development of fat digestion in early life

tests was $-25.4 \%$ (SD. $1.96 \%$ ). The natural enrichment of olive oil was $-29.5 \%{ }^{10}$

\section{Discussion}

Although infants over 1 month of age have cPDRs within the normal range previously reported for adults $^{7}$ and older children, ${ }^{10}$ neonates have cPDRs ranging from $0-32 \%$ in the first week of life to $7-26 \%$ in the last two weeks of the first month. It is important to consider what factors can affect the shape and magnitude of the PDR curves. After ingestion of a ${ }^{13} \mathrm{C}$ labelled substrate, the presence of labelled carbon dioxide in the breath indicates that the substrate has undergone the processes of digestion, absorption, and oxidation. A substrate can be selected so that any one of these processes is the rate limiting step. Isotope labelled triglyceride breath tests have been designed to test fat malabsorption due either to impaired digestion or mucosal absorption. ${ }^{14}$ Substrates that have been used in earlier studies include trioctanoin (glycerol trioctanoate) and triolein (glycerol trioleate). ${ }^{14}{ }^{15}$ However, trioctanoin is not a naturally occurring triglyceride and, because all three octanoic acid molecules are labelled, the result may reflect preduodenal as well as pancreatic lipolysis. The product of the lipolysis of triolein-namely, 2-oleyl-monoglyceride, may require bile salts for absorption. Thus diminished levels of bile salts found in liver disease may lead to a result erroneously interpreted as being due to insufficient pancreatic lipase.

To avoid these difficulties Ghoos et $a l^{16}$ developed a "mixed-triglyceride" in which two long chain fatty acids (at $\operatorname{Sn} 1$ and 3 positions) are hydrolysed by intraluminal lipases, releasing a monoglyceride with a medium chain fatty acid that is easily absorbed without bile salts and is rapidly oxidised releasing labelled carbon dioxide. This combination of fatty acids on the triglyceride molecule makes the rate limiting step lipolysis, rather than absorption or oxidation. Octanoic acid is not found in milk in any significant amounts ${ }^{6}{ }^{17}$ and is readily absorbed and oxidised when given orally and intravenously. It is therefore an ideal fatty acid to use for this purpose. This mixed-triglyceride or "MTG" is 1,3 -distearyl-2- $\left({ }^{13} \mathrm{C}\right.$-carboxyl)octanoyl glycerol.

The use of stable isotopes rather than radioisotopes has made such tests more attractive, particularly in paediatric research and practice. 
MTG has been used extensively to measure pancreatic function in adults with pancreatic disease. ${ }^{78}$ It has been used to assess pancreatic function in children with cystic fibrosis with the aim of better estimating enzyme supplement requirements. ${ }^{10}$ Studies of fat digestion have also been performed in neonates ${ }^{19}$ and infants, ${ }^{20}$ but both groups of investigators used trioctanoin. Van Aalst et $a l^{21}$ performed MTG breath tests on 14 term infants aged 3-121 days and showed a mean (range) cPDR of $31.3 \%$ (14.07-43.91\%). However, apart from one 3 day old infant, all were over 28 days old.

Investigators using the MTG breath test in adults are careful to standardise the test meal because many factors, such as rate of gastric emptying, pancreatic exocrine function, and gallbladder contraction, may affect the result of the breath test. For infants and small children we chose to use their normal feeds as a test meal. In older children and adults we used a test meal of two slices of buttered toast and a glass of milk, similar to that used by Vantrappen et $a .^{7}$

Delayed gastric emptying could have accounted for the low or zero cPDRs measured in some newborn babies, but time to peak did not differ significantly between infants of different ages, suggesting that the differences in $\mathrm{CPDR}$ were more likely due to differences in lipolysis. Moreover, using ${ }^{13} \mathrm{C}$-octanoic acid, gastric emptying rates in neonates with half times between 17 and 100 minutes have been measured. ${ }^{22}$ A delay of 360 minutes, which could have accounted for a zero cPDR, has not been described before.

PDR is directly proportional to carbon dioxide production rate. When we began this study, the convention for ${ }^{13} \mathrm{C}$ - breath tests was to estimate carbon dioxide production rate using the value of $5 \mathrm{mmol} / \mathrm{m}^{2} /$ minutes $^{12}$ and the Haycock equation for estimating surface area. ${ }^{13}$ However, in the light of studies we have since undertaken of children with cystic fibrosis using the MTG-breath test, we decided to measure carbon dioxide production directly using an indirect calorimeter ${ }^{23}$ in the last 22 tests. We therefore adapted a method pioneered for the measurement of energy expenditure in neonates. ${ }^{11}$

Figure 1 shows a wide range of $\mathrm{cPDR}$ in the early neonatal period ranging from zero to $34 \%$. The capacity to digest the MTG increased with advancing age. However, the increase occurred during the first two months, and by 50 days, all results lay within the normal range. Of the six infants with serial measurements, those with a cPDR below the normal range before 30 days subsequently rose to within this range. The preterm babies were tested at 33 weeks (10 days), 35 weeks (20 days) and 40 weeks gestation. At the earlier gestational age there was evidence of poor fat digestion. These findings conform with those of earlier studies and indicate that the ability to digest triglyceride increases rapidly, soon after birth. $^{45}$

The current convention for the MTG breath test is to express the result as cPDR. ${ }^{8}$ In an attempt to simplify the test, we examined three other expressions of PDR, namely peak PDR, time to peak, and cPDR at peak. There was a significant correlation between peak PDR and cPDR, suggesting the former could be used as an index of fat digestion, allowing the duration of the test to be shortened (fig 2). Time to peak did not correlate with $\mathrm{cPDR}$ and may be a function of gastric emptying or intestinal transit time.

The neonatal period is crucial for the assimilation of fatty acids, not only for energy, but also for neural and retinal tissue synthesis. It is reassuring to find that the capacity to digest the MTG increases rapidly during this time. We have reviewed elsewhere ${ }^{17}$ the physiology of fat digestion in early life, and in this study, we show that the MTG breath test can be used to measure lipolysis in infancy. The poor fat digestion found in some of the very young infants may have implications for the design of artificial, cow's milk based, formula feeds. The fatty acids found in the greatest concentration in human milk are palmitic (C16:0) and oleic (C18:1), the former found predominantly at the $S n-2$ position and the latter at the $S n-1$ and $S n-3$ positions. ${ }^{17}$ The sterioisometric structure of milk triglycerides not only determines the rates of fatty acid hydrolysis, and thereby absorption, but may also affect the absorption of other nutrients, such as calcium. ${ }^{24}$ Even though octanoic acid is rarely found in human milk, the MTG is a more physiological molecule than trioctanoin or triolein in that it combines fatty acids of different lengths in the triglyceride.

Human milk contains a lipase which may compensate for the "immature" pancreatic exocrine function found in the first weeks of life. ${ }^{317}$ It is activated by bile salts in the duodenum, and probably accounts for the greater fat absorption reported in preterm infants receiving human milk in addition to formula than from formula alone. ${ }^{25}$ We studied only formula fed infants, and it is possible that human milk might enhance fat digestion during early postnatal life. It is our intention to extend this study to breast fed infants, to measure the contribution of exogenous lipases to the process of fat assimilation.

We thank Elizabeth Dale, Jonathon Wells, Sergio Amarri and John Reilly for their help and advice, and the parents of the infants studied for their patience. We are also grateful to the EC Biomed Programme for its support.

\footnotetext{
1 Agostoni C, Trojan S, Bellu R, Riva E, Giovannini M. Neurodevelopmental quotient of healthy term infants at 4 months and feeding practice: the role of long-chain polyunsaturated fatty acids. Pediatr Res 1995;38:262-6.

2 Makrides M, Simmer K, Goggin M, Gibson RA. Erythrocyte docosahexaenoic acid correlates with the visual response of healthy, term infants. Pediatr Res 1993;33:425-7.

3 Hamosh M. Lipids and nutrition. In: Kelley VC, ed. Practice of Pediatrics. Philadelphia: Harper and Row, 1987:1-13.

4 van de Kamer JH, Weijers HA. Malabsorption syndrome. Fed Proc 1961;20:335-44.

5 Zoppi G, Andreotti G, Pajno-Ferrara F, Njai DM, Garburro D. Exocrine pancreas function in premature and full term neonates. Pediatr Res 1972;6:880-6.

6 Weaver LT, Manson WG, Amarri S. Measuring fat digestion in early life using stable isotope breath tests. Prenat Neonat Med 1997;2:116-23.

7 Vantrappen GR, Rutgeerts PJ, Ghoos YF, Hiele MI. Mixed triglyceride breath test: a noninvasive test of pancreatic lipase activity in the duodenum. Gastroenterology
1989;96:1126-34.
} 
8 Amarri S, Weaver LT. ${ }^{13} \mathrm{C}$-breath tests to measure fat and carbohydrate digestion in clinical practice. Clin Nutr $1995 ; 14: 149-54$.

9 Weaver LT, Thomas JE, McLean P, Harding M, Coward WA. Stable Isotope breath tests: their use in paediatric practice. In: Gastrointestinal Motility Disorders. Leuven: Centre for G.I. Research, University of Leuven: 1993, 155-68.

10 Amarri S, Harding M, Coward WA, Evans TJ, Weaver LT. ${ }^{13} \mathrm{C}$-mixed triglyceride breath test to assess pancreatic enzyme supplementation in children with cystic fibrosis. Arch Dis Child 1997;76:349-51.

11 Wells JCK. Energy metabolism in breast fed and formula fed infants. PhD thesis: University of Cambridge 1994.

12 Shreeve VW, Cerasi E, Luft R. Metabolism of (2${ }^{14} \mathrm{C}$ ) pyruvate in normal, acromegalic and $\mathrm{HGH}$-treated human subjects. Acta Endocrinologica 1970;65:155-69.

13 Haycock GB, Schwartz GJ, Wisotsky DH. Geometric method for measuring body surface area: a height-weight method for measuring body surface area: a height-weight 1978;93:62-6.

14 Watkins JB, Klein PD, Schoeller DA, Kirschner BS, Park R, Perman JA. Diagnosis and differentiation of fat malabsorption in children using ${ }^{13} \mathrm{C}$-labeled lipids: trioctanoin, triolein, and palmitic acid breath tests. Gastroenterology 1982;82:911-7.

15 Watkins JB, Schoeller DA, Klein PD, Ott DG, Newcomer $\mathrm{AD}$, Hofmann $\mathrm{AF} .{ }^{13} \mathrm{C}$-trioctanoin: a non-radioactive breath test to detect fat malabsorption. $\mathcal{F}$ Lab Clin Med 1977;90:422-30.

16 Ghoos YF, Vantrappen G, Rutgeerts PJ, Schurmans PC. A mixed-triglyceride breath test for intraluminal fat digestive activity. Digestion 1981;22:239-47.
17 Manson WG, Weaver LT. Fat digestion in the neonate. Arch Dis Child 1997;76:F206-F11.

18 Ghoos YF, Rutgeerts PJ, Hiele MI, et al. Use of Stable Isotopes in Gastroenterology: ${ }^{13} \mathrm{CO}_{2}$ Breath Tests. In: Use of Stable Isotopes in Clinical Research and Practice. 34th Edn. Munchen: Zucherschwerdt Verlag, 1988: pp 52-61.

19 Hoshi J, Nishida H, Yasui M, Ohishi M, Takahashi M. [13C] breath test of medium-chain triglycerides and oligosaccharides

20 McClean P, Harding M, Coward WA, Green MR, Weaver LT. Measurement of fat digestion in early life using a stable LT. Measurement of fat digestion in early life using a
isotope breath test. Arch Dis Child 1993;69:366-70.

21 Van Aalst K, Veerman-Wauters G, vd Schoor S, Ghoos YF, Devlieger $\mathrm{H}$, Eggremont $\mathrm{E}$. The ${ }^{13} \mathrm{C}$ mixed triglyceride breath test for assessment of lipase activity in preterm infants. F Pediatr Gastroenterol Nutr 1995;20:459

22 Veerman-Wauters G, Ghoos Y, van der Schoor S, et al. The ${ }^{13} \mathrm{C}$-octanoic acid breath test: a non-invasive technique to assess gastric emptying in preterm infants. 7 Pediatr Gastroenterol Nutr 1996;23:111-17.

23 Amarri S, Coward WA, Harding M, Weaver LT. Importance of measuring $\mathrm{CO}_{2}$ production rate when using ${ }^{13} \mathrm{C}$ breath
tests to measure fat digestion. Br f Nutr $1998 ; 79: 541-5$.

24 Lucas A, Quinlan P, Abrams S, Ryan S, Meah S, Lucas PJ. Randomised controlled trial of a synthetic triglyceride milk formula for preterm infants. Arch Dis Child 1997;77:F178-F84

25 Elemi B, Hamosh M, Scanlon JW, Salzman-Mann C, Hamosh P. Fat digestion in very low birth weight infants: effect of addition of human milk to low birth weight infant formula. Pediatrics 1981; 68: 484-9. 